\title{
DO DISCURSO À GRAMÁTICA: UM ENFOQUE CRÍTICO E FUNCIONAL DE GÊNEROS
}

\author{
(From discourse to grammar: a critical and \\ functional genres approach)
}

\author{
Edna Cristina Muniz da Silva ${ }^{1}$ \\ (Universidade de Brasília - UnB)
}

\begin{abstract}
Critical Discourse analysis investigates the use of the language in the social institutions e how social differences are formed linguistically. It requires a grammatical theory which relates language and social context to explain the differences between the texts and relate them to the contexts of culture and context of situation. This aim aligns with the theoretical assumptions of the Sistemic Functional Grammar, which connects the linguistic to the social practices in their contexts of culture and context of situation and provides the conscience of the genres and their purposes in the several social domains. The systemic-functional approach implies a specialized language to describe and analyze the contextual meanings of several texts.
\end{abstract}

Key-words: Critical Discourse Analysis; Systemic Functional Grammar; context of culture; context of situation; genres.

\section{RESUMO}

A Análise de Discurso Crítica (ADC) investiga o uso da linguagem nas instituições sociais e como as desigualdades sociais são constituídas linguisticamente. Requer uma teoria gramatical que relacione linguagem e contexto social para explicar as diferenças entre os textos e relacionálos aos contextos de cultura e de situação. Esse objetivo alinha-se com as premissas teóricas da Linguística Sistêmico-Funcional (LSF), que conecta a linguística às práticas sociais em seus contextos de cultura e de

1. Mestre e Doutora em Linguística pela Universidde de Brasília, onde atua como docente na Graduação e no Programa de Pós-Graduação em Linguística, dentro da área de Linguagem e Sociedade. Desenvolve pesquisas sobre gêneros do discurso e gramática sistêmico-funcional. Coordenadora do Curso de Letras $\mathrm{UAB} / \mathrm{UnB}$ desde 2008. 
situação e propicia a consciência dos gêneros do discurso e seus propósitos nos diversos domínios sociais. A gramática sistêmico-funcional emprega uma linguagem especializada para descrever e analisar os significados contextuais dos diversos textos.

Palavras-chave: Análise de Discurso Crítica; gramática sistêmicofuncional; contexto de cultura; contexto de situação; gêneros.

\section{Introdução}

O objetivo deste artigo é mostrar como a Análise de Discurso Crítica (ADC) e a Linguística Sistêmico-Funcional (LSF) compartilham uma visão dialética de linguagem, em que os significados construídos nos gêneros do discurso influenciam os contextos culturais e situacionais que, por sua vez, também influenciam os gêneros discursivos. A ADC é uma perspectiva teórica e metodológica que examina o uso da linguagem nas instituições sociais e as relações entre a linguagem, o poder e a ideologia. Investiga criticamente as desigualdades sociais expressas, sinalizadas e constituídas linguisticamente. Para isso, lança mão das categorias analíticas da linguística sistêmico-funcional. A abordagem sistêmico-funcional provê a descrição detalhada das funções e estruturas dos textos e relaciona as variáveis do contexto de situação à organização gramatical e semântica da linguagem para fornecer explicações funcionais sobre a dimensão contextual dos textos. Além disso, desenvolve descrições sobre as estruturas dos diferentes gêneros e procura entender como os gêneros se relacionam entre si e como se transformam em outros gêneros. Essa abordagem reconhece que as diferenças entre os textos são o reflexo de uma dimensão mais abstrata do contexto, que é a ideologia.

\section{A Análise de Discurso Crítica e os gêneros do discurso}

Na Análise de Discurso Crítica, a análise interdiscursiva de textos constitui o nível mediador crucial para integrar a análise 
linguística à análise social (Fairclough trad. 2001; Chouliaraki e Fairclough, 1999). Fairclough propõe o emprego do termo 'semiose' para referir-se a qualquer modalidade semiótica de uso de linguagem - oralidade, escrita, imagens, por ser um elemento dialeticamente interconectado com outros elementos de práticas sociais como: as formas de atividade, seus meios e suas tecnologias; as relações sociais e suas formas institucionais; e as pessoas e suas crenças, seus valores, suas emoções, suas histórias. Em outras palavras, a semiose figura nas práticas sociais mediante discursos, gêneros e estilos, e o elemento semiótico de uma rede de práticas sociais é uma ordem de discurso, que por sua vez articula gêneros, discursos e estilos específicos. Portanto, a análise interdiscursiva de textos é fundamental porque, ao combinar e mesclar gêneros, discursos e estilos em um texto por seus traços semânticos, léxico-gramaticais e fonológicos, configura-se um plano intermediário entre a análise linguística e a análise social.

Fairclough (2003) entende como gênero o aspecto discursivo convencional de modos de agir e interagir estáveis, definidos pelas práticas sociais e suas inter-relações no curso dos eventos sociais. Por serem construídos socialmente, fornecem os sinais para que os sujeitos interpretem as particularidades de uma interação comunicativa específica. Todos os membros de uma comunidade se apropriam diferentemente - no tempo e no espaço - dos diversos gêneros e de seus significados, que são construídos e modificados coletivamente o tempo todo no processo contínuo de interação e colaboração em práticas sociais compartilhadas. Isso ocorre porque parte da ação social implícita no uso ou reconhecimento de um gênero é política, dado que os gêneros não são utilizados igualmente por todas as pessoas, mesmo que participem da mesma comunidade discursiva (por exemplo, não são todas as pessoas que produzem textos - e mesmo assim, quando produzem são textos de gêneros específicos, e não todos; da mesma forma, também não são todos que leem textos), porque as formas de interação são constituídas por tipos particulares de relações sociais entre os agentes da interação, as quais se diferenciam conforme o poder e a solidariedade (Fairclough, 2003). 
Os gêneros variam quanto à sua estabilização, fixidez e homogeneização. Alguns gêneros - como o artigo acadêmico - são ritualizados. Outros são completamente variáveis - como os textos publicitários. Na época atual, em que passamos por um período de transformações sociais rápidas e profundas, há uma tensão entre a estabilização, força de consolidação da nova ordem social, e o fluxo das mudanças. As transformações sociais decorrentes do processo de globalização produzem mudanças nas inter-relações das práticas sociais e, consequentemente, mudanças nas formas de ação e interação, que levam a mudanças nos gêneros. Nesse caso, cabe verificar o que ocorre efetivamente nas práticas quanto à variedade de atividades que um gênero pode contemplar.

\section{Gêneros, textos e contextos: a perspectiva sistêmico- funcional}

Os gêneros, segundo a perspectiva sistêmico-funcional, são definidos em termos do seu propósito social (Eggins e Martin, 2000), isto é, implicam o uso da linguagem para a realização de atividades culturalmente estabelecidas. As diferenças de propósitos, motivadas pelo contexto sócio-cultural, são refletidas na estrutura dos textos, que apresentam padrões de linguagem típicos para cada gênero. A estrutura linguística dos textos codifica os significados do contexto imediato cujas categorias - campo, relação e modo - descrevem a variação dos textos em termos funcionais.

A abordagem sistêmico-funcional provê a descrição detalhada das funções e estruturas dos textos (Halliday e Matthiessen, 2004) e relaciona as variáveis do contexto de situação à organização gramatical e semântica da linguagem para fornecer explicações funcionais sobre a dimensão contextual dos textos. Além disso, desenvolve descrições sobre as estruturas dos diferentes gêneros e procura entender como os gêneros se relacionam entre si e como se transformam em outros gêneros. Essa abordagem reconhece que as diferenças entre os textos são o reflexo de uma dimensão mais abstrata do contexto, que é a 
ideologia (Eggins e Martin, 2000). A ideologia tem a ver com as posições de poder, as tendências políticas e as suposições que os agentes sociais trazem para os seus textos.

Utilizamos a língua para falar sobre a nossa experiência de mundo, para descrever eventos e as entidades que os envolvem; para interagir com as outras pessoas, bem como influenciar o seu comportamento, além de expressar nossos pontos de vista e também solicitar às outras pessoas que expressem seus pontos de vista sobre tudo. Para usarmos a língua, precisamos organizar as mensagens a fim de indicar aos outros como se articulam entre si e como se inserem no contexto sociocultural em que falamos ou escrevemos.

A noção de função é um princípio fundamental da linguagem que nos permite estudá-la para entender como se organiza e o que as pessoas fazem com ela. Função significa uso. As funções da linguagem representam o modo como as pessoas atingem diferentes propósitos pela fala e pela escrita, identificadas por meio de significados entrelaçados na construção do discurso.

Halliday distingue três funções da linguagem: ideacional, interpessoal e textual. A função ideacional, que se refere ao conteúdo proposicional das orações, compreende o sistema de transitividade, em que a linguagem serve para a expressão da experiência do falante, incluindo a sua própria consciência. Ao cumprir essa função, a linguagem estrutura a experiência e contribui para determinar nossa visão do mundo. A função interpessoal se refere ao modo e à modalidade (as diferenças entre os enunciados, como perguntas e ordens, por exemplo), segundo a qual a linguagem serve para estabelecer e manter relações sociais, expressar os papéis sociais e realizar ações. Ao permitir a interação, a linguagem também serve para a expressão e desenvolvimento da personalidade do indivíduo. A função textual, que se refere ao modo como a estrutura gramatical e a estrutura de entonação das orações se relacionam nos textos, permite às pessoas construir textos vinculados a uma situação. Um dos aspectos da função textual é estabelecer relações de coesão entre as orações, já que um texto não é a soma de orações aleatórias. 
A frase, a oração e o período codificam simultaneamente esses três significados - ideacional, interpessoal e textual, por meio dos sistemas de significados (semântica) e dos sistemas das frases e das palavras ou dos sinais (léxico-gramática), que apresentam o potencial das palavras e o modo como são combinadas e organizadas para formar os textos. Em síntese, a gramática sistêmico-funcional descreve e analisa as escolhas gramaticais e lexicais dos sistemas das frases e das palavras, permitindo-nos saber como a língua é usada para realizar os significados nos textos.

De acordo com a abordagem sistêmico-funcional, o texto é uma unidade semântica cuja estrutura linguística e genérica constituise em um meio para a construção de significados, que ocorrem em dois contextos - o de cultura, que se refere ao modo de vida, aos costumes, aos valores e às crenças das pessoas que vivem em determinada comunidade e sociedade; e o de situação, que se refere aos momentos e lugares específicos em que os textos são efetivamente utilizados. A combinação entre os contextos de cultura e de situação resultam nas semelhanças e diferenças entre os diversos textos e gêneros.

O contexto de situação é constituído de três dimensões - campo, relações e modo, que exercem influência sobre as nossas escolhas linguísticas porque refletem as três principais funções da língua: falar sobre os acontecimentos, eventos, fatos; interagir com as pessoas e expressar pontos de vista; organizar as ideias, os conhecimentos e as informações em um texto coerente.

De um modo geral, os textos podem compartilhar significados e/ou elementos estruturais. Sempre que os textos compartilham significados ideacionais, interpessoais e textuais pertencem ao mesmo registro; já quando compartilham propósitos definidos culturalmente, apresentam elementos estruturais opcionais e obrigatórios, pertencem ao mesmo gênero. $\mathrm{O}$ conhecimento sobre registro e gênero é fundamental para as pessoas criarem seus próprios textos, bem como reconhecerem a diversidade dos tipos textuais (Butt et al., 2003: 8).

No dia-a-dia participamos de situações familiares, que fazem parte do nosso contexto cultural, razão por que reconhecemos e 
compreendemos os significados construídos pelas outras pessoas. Isso acontece porque compartilhamos o mesmo conhecimento cultural. Sempre que escrevemos ou falamos, fazemos seleções do sistema lexical e gramatical da Língua Portuguesa (no nosso caso, da variante brasileira) para criarmos significados relativos ao campo, às relações e ao modo de um contexto situacional.

Entendemos a língua por meio dos gêneros e dos textos que os materializam. As palavras e as estruturas linguísticas codificam os significados em um texto por meio da sua textura e estrutura. Adotar uma percepção funcional da língua significa pensar a língua como um processo de construção dos significados, que são tecidos coerentemente para criar uma unidade de sentido e de propósito a partir de um contexto cultural e social. O contexto e o texto estão de tal forma entrelaçados que, para compreender um texto, é fundamental investigar o seu contexto, da mesma forma que é preciso saber como usar o conhecimento sobre o contexto para entender como os textos funcionam.

Texto e contexto se associam na construção dos sentidos do que é dito ou escrito nos ambientes sociais em que se desenvolvem e são interpretados (Halliday e Hasan, 1991: 5). Nesse sentido, toda língua é compreendida em seu contexto de situação e de cultura porque os textos que produzimos sempre desempenham algum papel em algum contexto. $\mathrm{O}$ contexto de situação é descrito por Halliday em termos de três variáveis - campo, relações e modo -, que são realizadas através das metafunções da linguagem: ideacional, interpessoal e textual

A descrição das variáveis campo, relações e modo possibilita a identificação de significados, palavras e estruturas possíveis ou prováveis em determinado contexto. Isto é, ao explorar o campo de uma situação, podemos identificar as palavras e as estruturas linguísticas que constroem sentidos sobre a experiência (significados ideacionais); ao explorar as relações da situação, identificamos as palavras e as estruturas para estabelecer relações interpessoais e expressar pontos de vista (significados interpessoais); e explorar o modo de uma situação significa identificar palavras e estruturas que 
organizam esses sentidos em um texto em determinado contexto (significados textuais).

Os textos que compartilham o mesmo propósito social em uma cultura também compartilham o mesmo padrão estrutural, ou o mesmo gênero. Investigar os padrões estruturais de diferentes gêneros significa captar a riqueza do repertório dos elementos textuais, que constituem a base para a elaboração de textos coerentes, sensíveis às complexas demandas culturais.

Para descrever o conhecimento sobre o uso da língua e o modo como se dá a construção dos significados na perspectiva sistêmicofuncional, é preciso empregar uma linguagem especializada, ou metalinguagem, cuja finalidade é descrever o que a língua faz, analisar como a língua faz o que faz, bem como comparar e contrastar o uso da língua nos diversos textos e seus contextos.

Existem três sistemas, que representam as escolhas que fazemos na construção das orações, relacionados às três metafunções: Transitividade, Tema/Rema e Modo/Modalidade. Em outras palavras, isso significa que os significados ideacionais, formadores do Campo, se realizam através do léxico e da gramática pelo sistema de Transitividade, que interpreta e representa a nossa experiência no mundo em termos de participantes, processos e circunstâncias.

Os significados interpessoais formadores da Relação se realizam pelos sistemas de Modo e Modalidade. O sistema de Modo é o principal recurso para estabelecermos as trocas comunicativas com os nossos interlocutores aceitando e atribuindo papéis como dar e solicitar bens e serviços ou informações através das orações declarativas, das orações interrogativas quando fazemos perguntas e das orações imperativas quando solicitamos algo ou damos ordens.

Os significados textuais formadores do Modo referem-se à interação da informação interpessoal e ideacional no texto e nas relações que estabelece com o contexto. Os significados textuais são realizados léxico-gramaticalmente pelo sistema de Tema/Rema. As seleções de Tema/Rema estabelecem a orientação ou o ângulo dos aspectos interpessoais e ideacionais da oração. 


\subsection{A oração como representação}

Os três componentes da gramática ideacional da oração um processo que se desenvolve ao longo do tempo, participantes envolvidos nesse processo e circunstâncias associadas ao processo - são categorias semânticas que explicam de modo geral como os fenômenos da nossa experiência de mundo são construídos por meio das estruturas linguísticas e são organizados de modo a fornecer uma configuração ou esquema dessa experiência.

Os elementos circunstanciais (grupo adverbial ou sintagma preposicional) geralmente são opcionais e ampliam a oração do ponto de vista temporal, espacial, causal, de modo etc.; já os participantes (grupo nominal) são inerentes ao processo (grupo verbal), visto que toda oração tem pelo menos um participante, e os processos são constituintes centrais na configuração da oração ideacional.

Gramaticalmente, os tipos de processos construídos pelo sistema da Transitividade distinguem basicamente entre as experiências do mundo físico, das ações e dos eventos nas orações de processos materiais, e aquelas do mundo da consciência, da percepção, da emoção e da imaginação nas orações de processos mentais. A gramática também codifica processos de identificação e classificação nas orações de processos relacionais ('ser' e 'ter'). Portanto, os principais tipos de processos do sistema da Transitividade são os materiais, os mentais e os relacionais. Entretanto, na fronteira entre os processos materiais e mentais, estão os processos comportamentais, que representam as manifestações dos processos da consciência ('rir', 'examinar', por exemplo) e estados fisiológicos (como 'ouvir', 'dormir'). Entre os processos mentais e relacionais, localizam-se os processos verbais, que se referem às relações simbólicas construídas na consciência humana e realizadas pela linguagem, como 'dizer', por exemplo. E entre os processos relacionais e materiais estão os processos existenciais, que se referem à existência ou ao acontecimento das coisas.

As orações de processo material - do fazer e acontecer, têm a ver com a nossa experiência do mundo material e envolvem ações físicas: correr, arremessar, cozinhar, sentar, etc. O agente desse 
tipo de ação denomina-se Ator e qualquer processo material tem um Ator, mesmo que não seja mencionado na oração. As orações de processo mental se referem à experiência do mundo interno da nossa consciência, como pensar, imaginar, gostar, querer, ver, etc. Essas orações diferenciam gramaticalmente quatro tipos de sentir: perceptivo (ver, ouvir, etc.), cognitivo (imaginar, escolher, descobrir, decidir, conhecer, compreender etc.), desiderativo (desejar, querer) e emotivo (sentir, gostar, apreciar, odiar).

As orações de processo relacional ligam um participante à sua identidade ou descrição e, por isso, codificam dois tipos de processos: atributivos, que relacionam um participante a suas características gerais; e identificativos, que relacionam um participante à sua identidade, papel ou significado. As orações de processo comportamental referemse aos comportamentos fisiológicos e psicológicos, ou seja, ações que refletem estados mentais, como respirar, sorrir, saborear, pensar, ver, etc. Apresentam características tanto dos processos materiais quanto dos mentais, pois em parte referem-se a uma ação, que tem de ser realizada por um ser consciente.

As orações de processo verbal referem-se aos verbos de 'dizer', que são facilmente reconhecidos porque se referem à transferência de mensagens através da linguagem. As orações de processo existencial representam algo que existe ou acontece e apresentam apenas um participante: o Existente. Em português são identificadas como orações sem sujeito pela gramática tradicional, cujos verbos mais comuns são 'haver' e 'ter' e os que indicam fenômenos meteorológicos. A função da oração existencial é anunciar a existência de uma situação.

\subsection{A oração como troca}

Um dos principais objetivos da comunicação é estabelecer e manter laços sociais entre as pessoas através da interação, que é sempre motivada por um propósito: influenciar o comportamento ou as atitudes das pessoas, por dar informações ou obtê-las. Isso significa que a gramática nos fornece os recursos para interagirmos por meio da língua. 
Em termos gramaticais, os propósitos fundamentais em qualquer troca comunicativa são dar ou solicitar informação, situação em que a língua assume uma função constitutiva, essencial, ou dar ou solicitar bens-e-serviços, quando a língua assume uma função auxiliar ou secundária. Isto é, a língua é usada como meio para alcançar objetivos não-linguísticos. De acordo com Halliday e Matthiessen (2004:107), existem quatro funções discursivas, e cada uma delas associa-se a estruturas gramaticais específicas: dar informação (asserções, expressas por orações declarativas), solicitar informação (perguntas - expressas por orações interrogativas), oferecer bens-eserviços (ofertas - não estão associadas a um tipo oracional específico) e solicitar bens-e-serviços (ordens, pedidos, súplicas - expressas por orações no modo imperativo). As orações que materializam essas quatro funções denominam-se 'proposições', que é a função semântica de uma oração nas trocas de informação utilizada nas declarações e nas perguntas; e 'proposta', que é a função semântica de uma oração nas trocas de bens-e-serviços, empregada para referir-se a ofertas e ordens ou pedidos.

Os significados interpessoais da linguagem construídos nas trocas de informação e de bens-e-serviços se estruturam lexicogramaticalmente. A forma mais comum utilizada para dar informação é a declaração; para solicitar informação utilizamos perguntas e para solicitar bens-e-serviços, usamos um comando ou uma ordem. Linguisticamente não existe uma forma típica para a troca de bens-e-serviços, porque nessa situação a linguagem é empregada para se fazer coisas.

Nas trocas de informação, os falantes apresentam suas proposições, que poderão ser aceitas ou não pelos seus ouvintes. Há dois tipos de modalidade, que assume significados diferentes nas proposições e nas propostas. Nas proposições, em que são trocadas informações, a modalidade é denominada modalização e refere-se à validade da informação apresentada em termos de probabilidade (possível/ provável/ certo) ou frequência (às vezes/ frequentemente/ sempre). Já nas propostas, que giram em torno de bens-e-serviços, a modalidade é denominada modulação e diz respeito à confiança que 
o falante demonstra para ser bem sucedido na troca comunicativa. $\mathrm{Na}$ ordem, refere-se ao grau de obrigação para a outra pessoa cumpri-la (permitido/ aconselhável/ obrigatório), e a oferta se refere ao grau de inclinação do falante para preenchê-la (habilidade/ boa vontade/ determinação).

A modalidade envolve vários graus e escalas, dependendo do grau de certeza expresso pelo falante sobre a validade de uma proposição ou o grau de pressão para que alguém realize uma ordem. Também pode expressar o grau de comprometimento do falante em relação à validade do que diz. Isso tem implicações importantes na análise de distintos gêneros.

As proposições podem indicar o grau de responsabilidade do falante que pode expressar o seu ponto de vista de maneira subjetiva, ou pode expressá-lo de maneira objetiva, para que pareça ser uma qualidade do próprio evento. Em um texto, a modalidade tem uma fonte, que geralmente é o falante. A modalidade evidencia que o falante expressa uma visão pessoal em relação ao fato objetivo.

Uma outra dimensão dos significados interpessoais em um texto refere-se à Avaliação que, expressa frequentemente por escolhas lexicais, é uma indicação sobre como o falante pensa que algo - pessoa, coisa, ação, evento, situação, ideia - é bom ou mau. É interessante verificar quais as escalas de valores estabelecidos nos diferentes gêneros. A escolha da avaliação reflete e reforça os valores ideológicos da cultura. De acordo com Martin (2000), existem três grandes categorias de valores em nossa cultura, que podem apresentar perspectivas positivas ou negativas: Afeto, Julgamento e Apreciação. O Afeto focaliza os sentimentos do avaliador sobre coisas e eventos; o Julgamento e a Apreciação recaem sobre as qualidades do que é avaliado. O Julgamento refere-se à avaliação de uma pessoa; a Apreciação diz respeito à avaliação de coisas e eventos. Essa divisão reflete os tipos de valores atribuídos aos seres humanos e às coisas.

A oração se estrutura linguisticamente para construir significados que tornam possíveis as trocas linguísticas - sejam bens-e-serviços ou informação - por meio da correlação entre 
as categorias semânticas ou as funções da fala - oferta, ordem, declaração, pergunta.

\subsection{A oração como mensagem}

Quando adotamos a perspectiva da metafunção textual para analisar a linguagem, percebemos como os falantes constroem as suas mensagens de modo que participem de um evento de linguagem em curso. Constantemente os falantes organizam o modo como suas mensagens são fraseadas ('worded') para indicarem a seus ouvintes como as diferentes partes da mensagem se conectam.

A oração também se configura estruturalmente para expressar significados textuais e transmitir uma mensagem por meio do sistema do Tema, que se constitui de dois elementos funcionais: Tema (o ponto de partida para uma mensagem) e Rema (a informação nova sobre o ponto de partida). Para Halliday e Matthiessen (2004:64), tipicamente o Tema contém uma informação familiar ou 'dada', ou já mencionada no texto, ou familiar ao contexto. O Tema pode ser identificado com base na ordem dos elementos na oração, pois é o elemento que vem primeiro na oração. O Rema é tudo o que não é Tema, e tipicamente contém a informação 'nova', que não é familiar.

De acordo com Eggins (2004:308; 320), é melhor fazer a análise do Tema após analisar a estrutura oracional de Transitividade e de Modo, porque primeiramente as estruturas de Transitividade são construídas, segmentadas e ligadas por meio das relações lógicas para que então se inicie a interação. Assim sendo, é necessário construir a estrutura de Modo fazendo as escolhas interpessoais. Embora os significados ideacionais e interpessoais sejam essenciais para a criação do texto, não são suficientes, pois ainda falta o sistema textual, para articulá-los com coesão e coerência.

Embora o Tema não introduza em um texto novos conteúdos ou novas dimensões interpessoais, a sua seleção é essencial para que o texto faça sentido e seja coeso. A seleção do padrão temático é fortemente influenciada pela variável de registro Modo, pois, havendo variação do modo - distinção entre a linguagem falada (interativa) 
e a escrita (monológica) -, há também variação na estrutura Tema/ Rema. Por exemplo, quando a Modalidade é tematizada, a interação é evidenciada; do contrário, o texto pode criar sua autoridade e distanciamento.

As escolhas de Temas tópicos se relacionam à variação de modo entre os textos. Nas interações face-a-face, o ponto de partida das nossas mensagens geralmente são assuntos que nos dizem respeito. Já na linguagem escolar, sobretudo a escrita, o modo requer a Tematização de abstrações, já que não partimos de nossas próprias experiências, mas construímos generalizações a respeito de pessoas, situações, causas e efeitos. É através de seus Temas tópicos que os textos revelam suas estratégias para cumprirem os seus propósitos discursivos.

A estrutura Tema/Rema, que é um componente essencial na construção da coesão e coerência textual, também pode ser considerada no nível do parágrafo. Pode-se dizer que cada parágrafo contém um tema, por meio do qual o escritor mostra qual é o ponto de partida do que se seguirá no texto. O tema do parágrafo é denominado por Martin e Rose (2003) como hipertema, ou tópico frasal, cuja função é justamente antecipar o que será dito na sequência do texto. Para esses autores, escritores e falantes habilidosos utilizam diferentes níveis de estrutura textual para reorientar continuamente a expectativa de seus leitores e ouvintes quanto ao que está sendo dito.

O sistema Tema/Rema organiza-se paralelamente ao sistema de coesão, que dá textura ao texto, e ao sistema de informação Nova e Dada, porque os falantes estruturam seus textos em unidades informacionais para sinalizarem o ponto de partida de suas mensagens. O padrão não-marcado do fluxo informacional é que geralmente a informação Dada, conhecida, encontra-se no Tema da oração, e a informação Nova no Rema.

Segundo Halliday e Matthiessen (2004: 105), a organização temática das orações constitui o fator mais relevante para o desenvolvimento de um texto, pois o Tema fornece as condições para a existência do Rema. O elemento proeminente na estrutura Tema/ 
Rema é o Tema. Esses autores propõem que a análise da estrutura temática de um texto, oração por oração, permite que conheçamos a sua textura e o modo como o escritor torna claros os seus propósitos subjacentes.

\section{Considerações finais}

O estudo de textos e gêneros como modos de prática social deve ser articulado a uma teoria social do discurso - a Análise de Discurso Crítica, que focaliza como o discurso é configurado nas práticas sociais, e à perspectiva da linguística sistêmico-funcional, que provê suporte teórico para análise da gramática e da estrutura textual relacionadas ao contexto social e ao propósito cultural dos textos. Por um lado, o uso da gramática sistêmico-funcional para o estudo e a análise de textos envolve uma descrição gramatical que privilegia a relação de textos aos seus contextos de cultura e de situação, ao mesmo tempo em que propicia a consciência de que a estrutura dos gêneros relaciona-se a seus propósitos nas práticas sociais. Por outro lado, ao examinar questões sociais que se manifestam discursivamente através dos gêneros nos diferentes domínios sociais, a ADC enfatiza a relação entre língua, poder e ideologia, sobretudo, ao desvelar as estruturas linguísticas que revelam as relações de dominação e desigualdade.

\section{Referências bibliográficas}

Butt et. al. Using functional grammar: an explorer's guide. 2. ed., Sidney: Macquarie University, 2003.

Chouliaraki, L. \& Fairclough, N. Discourse in late modernity: rethinking critical discourse analysis. Edinburgh: Edingurgh University Press, 1999.

Eggins, S. \& Martin, J.R. Géneros y registros del discurso. In Van Dijk, T.A. El discurso como estructura y processo, Barcelona: Gedisa, 2000. 
Fairclough, N. Analysing discourse: textual analysis for social research. Londres \& Nova Iorque: Routledge, 2003.

. Discurso e mudança social. Coord. trad., rev. e pref. Izabel Magalhães. Brasília: Editora Universidade de Brasília, 2001.

Halliday, M.A.K. e Hasan, R. Language, context, and text: aspects of language in a social-semiotic perspective. Oxford University Press, 1991

Halliday, M.A.K. e Matthiessen, C.M.I.M. An introduction to functional grammar. 3. ed., Oxford, Londres: Arnold, 2004.

Recebido em: julho de 2010 Aprovado em: setembro de 2010 ednacris@gmail.com 